\title{
Nodding and napping in medical lectures: an instructive systematic review
}

\section{ABstract}

A comprehensive, international systematic review, spanning more than 100 years of data collection, suggests that soporific lectures at medical meetings are common, annoying and persistent. Low lights and boring material are prominent risk factors for nodding off during presentations. Extreme remedial measures are warranted.
A year ago, we undertook an original investigation into the incidence of, and risk factors for, nodding off at scientific presentations (the nodding at presentations, or NAP, phenomenon). The resulting report ${ }^{1}$ generated considerably more interest than our other recent publications, which we strategically cite here..$^{2-4}$ Thus encouraged, we decided to write a follow-up paper.

Although we feel that shameless pandering to the editors is in itself a worthy justification for writing the present article, we must admit that we have no new data to offer. Some might see this as an insurmountable obstacle. However, several readers of our earlier work ${ }^{1}$ alerted us to a vaguely similar paper from $1983 ;{ }^{5}$ this enables us to continue to publish, while avoiding the bother of doing much new work, by conducting a systematic review. Readers of a utopian bent, inclined to believe that if only there were enough carefully assembled information then doctors would know what to do, might ask why we did not undertake a meta-analysis. In our experience, meta-analysis is to analysis as metaphysics is to physics and, in any case, there are too many rules to follow for meta-analyses and too little evidence that following them improves outcomes.

To encourage readers to actually read our systematic review, we have made it useful by highlighting illustrative points. These the young can read for their instruction, the reflective to their dismay, the old to the usual good end of reading to confirm what they already know, and the editors at their own risk. For example, how many readers have noticed that by including citations to our own work we have increased its value in the eyes of the members of peer-review agencies, who have taken to counting such things? How many more were aware that by citing recent $C M A J$ papers we have increased the citation index of $C M A J$, thereby giving small recompense to the editors for the otherwise unrewarded but - judging by the emails in response to our earlier study - extremely widely read holiday issue?

\section{Methods}

We did not limit ourselves to the 2 papers that we had on hand. ${ }^{1,5}$ Conveniently, an interested reader informed us of a

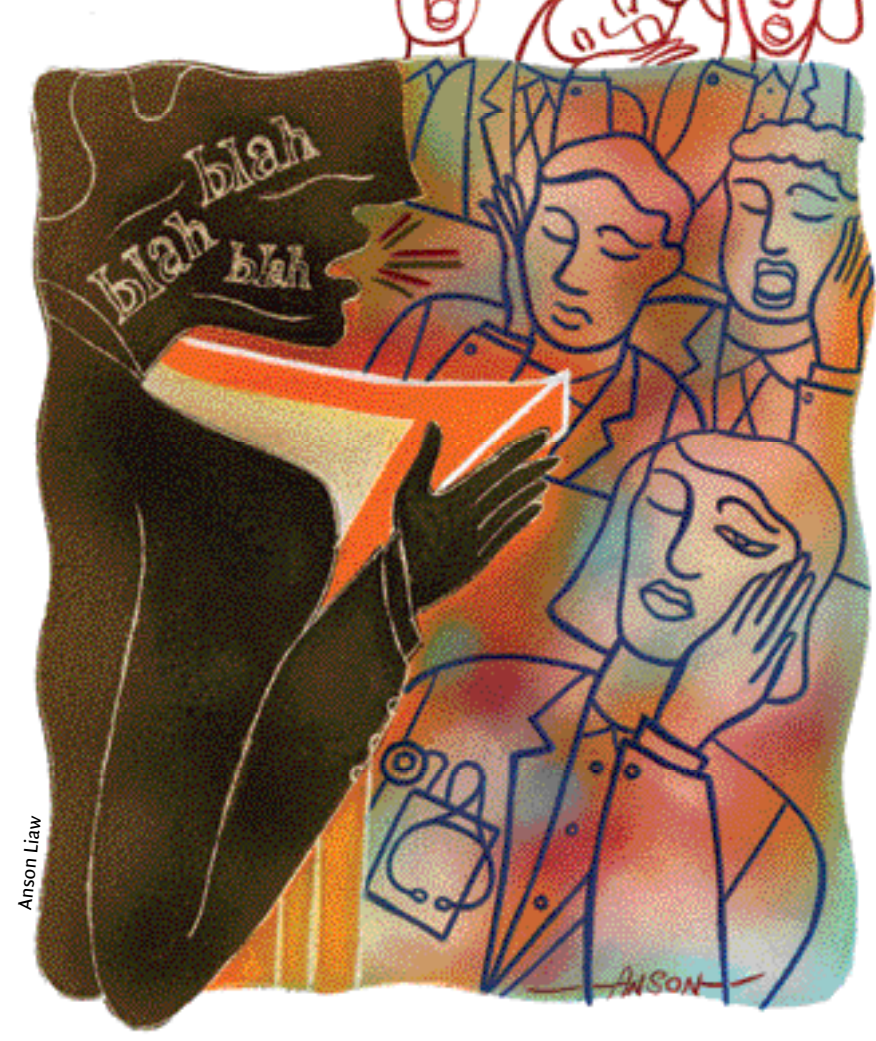

third paper as we were contemplating this project. In 1885 Francis Galton published (in Nature, no less) on the topic of fidgeting at scientific lectures. ${ }^{6}$ We considered it such a remarkable innovation to make a Nature paper out of boredom (rather than the other way around, as is conventional) that we included it, even though Galton used no statistics, studied no women, presented no multivariate analyses and made no declaration of conflict of interest.

Other correspondents had brought to our attention still more papers (usually their own) that they felt to be congruent with our original results, noting, with varying degrees of pique, that we had not cited their work. Although we fail to see the connection between their studies and ours, these researchers did not write to us in vain: we were able to knowingly exclude their work from the present systematic review, rather than simply being unaware of it. Other papers that appeared in the same $C M A J$ issue as ours and had vaguely neurological themes ${ }^{7,8}$ were of no greater relevance, but by citing them we can further reward $C M A$ Ps editors for publishing these holiday articles.

To be sure that we had missed no important papers, we looked up our article in PubMed and then pushed the "Related articles" button a few times. This revealed no new relevant papers but did lead to an interesting observation. The report of a consensus conference on migraine turned up on each search. ${ }^{9}$ Intrigued, we pushed on, searching (with the 
term "meta-analysis") the terms "Crohn's disease," "do not resuscitate" and "Hogan's foot." The headache meta-analysis popped up each time ( $p$ value for trend $<$ o.ooor). However, we excluded this paper on the grounds that in our earlier investigations we had done all that we needed to do to rule out mass migraine as a cause of the NAP phenomenon. (Instruction for the young: Putting YOUR TITLE IN CAPS and using "meta-analysis" as a keyword appears to be a way to ensure that your paper will receive widespread attention.)

The PubMed search revealed a few other reports. We thus also considered a paper on audience response systems, ${ }^{10}$ another entitled "Presentations at professional meetings: notes, suggestions and tips for speakers" ${ }^{11}$ and a third that was a prospective study of factors associated with successful lecturing. ${ }^{12}$ We immediately dismissed each on methodologic grounds. (Instruction for the young: This is the best way to handle work by researchers who might compete with you; Galton, by contrast, is safely dead.)

\section{Results}

(Instruction to the young: Presenting cobbled-together work under the heading "Results" can make it look as though you've done something that, if not worthwhile, is at least new.) Of the 596 physicians and scientists studied in the articles we included in this review, many napped during lectures and a great many scientists fidgeted. Nodding was common, but whether in agreement with the speaker or in reverie remains undetermined. Snoring was noted in fully two-thirds of the papers reviewed. Boring audiovisual aids were found to be an important risk factor for the NAP phenenomon in $67 \%$ of the studies under consideration, as was low light. Dreaming and fantasizing appear to be more common during scientific presentations than actual sleeping, likely as defence mechanisms.

\section{Discussion}

This comprehensive, international systematic review, spanning more than roo years of data collection, allows us to say with confidence that soporific lectures at medical and scientific congresses are an annoying and persistent problem throughout the Western world. Although this finding will likely spawn calls for remedies ranging from the banal to the extreme, we must caution readers that in the absence of evidence from randomized controlled trials no firm conclusions can be drawn. (Instruction to the young: The absence of such evidence also means that we are not constrained in our recommendations by contrary data.) We suggest (grade D recommendation) that lecturers should aim to prepare lectures that are precise and pithy and that, if there is to be a trade-off, pith should be favoured over precision. Failing that, people who present boring lectures should be stopped from doing so, with the maximum vigour that local norms will allow.

Our data must be interpreted with caution. (Instruction to the young: It is necessary to include an admission of weaknesses in your research report, but important to present these with a positive spin.) The period of observation is only about Ioo years, and it might well be that the problem is even more in- tractable. Nevertheless, the consistency of these multiple observations over decades that span the evolution of audiovisual aids points out that even advanced technology in itself cannot compensate for the effects of boring content or monotone delivery. Also, we have studied only a few countries. Whether these findings apply to congresses in sunny climes or to CME cruises is a matter of some concern and is motivating further inquiries by our group. Moreover, as ours ${ }^{1}$ was the only recent study, we were unable to make a nuisance of ourselves by writing to other investigators and pestering them for their data under the vague threat of being immortalized as uncooperative on a Cochrane $\mathrm{CD}$, an increasingly common practice to which we have been subject and for which we had looked forward to some payback.

The lack of careful research on this problem highlights the shocking extent to which society in general and governments in particular take physician time for granted. From an economic point of view, even a meeting at which roo physicians who bill at a rate of \$200 per hour nod off during a boring I-hour presentation carries a \$20 ooo cost. Given that between grand rounds, CME lectures, pharmaceutical consultancies, journal clubs, annual meetings, regional programs and city-wide supper clubs masquerading as information exchanges about roo such meetings must be occurring daily in Canada, the annual cost is about \$75 million, roughly the purchase price of the naming rights for I. 5 faculties of medicine every 2 years. And that's without considering GST or the added time for completing Maintenance of Certification diaries. Clearly, this is an area that requires much more grant money than it has been afforded until now.

\section{Kenneth Rockwood \\ Dalhousie University \\ Halifax, NS \\ Christopher J. Patterson \\ McMaster University \\ Hamilton, Ont. \\ David B. Hogan \\ University of Calgary \\ Calgary, Alta.}

\section{REFERENCES}

I. Rockwood K, Hogan DB, Patterson CJ; for the Nodding at Presentations (NAP) Investigators. Incidence of and risk factors for nodding off at scientific sessions. CMAJ 2004;I7I(2):I443-5.

2. Rockwood K, Song X, MacKnight C, et al. A global clinical measure of fitness and frailty in elderly people. CMAJ 2005;I73(5):489-95.

3. MacKnight C, Hogan DB. Physician supply: future tense. CMAJ 2003;I69(8):750-I.

4. MacMillan HL, Patterson CJS, Wathen CN, et al. Screening for depression in primary care: recommendation statement from the Canadian Task Force on Preventive Health Care. CMAJ 2005;172(I):33-5.

5. Harvey RF, Schullinger MB, Stassinopoulos A, et al. Dreaming during scientific papers: effects of added extrinsic material. $B M J 1983 ; 287: 1916-9$.

6. Galton F. The measure of fidget. Nature June 25, I885.

7. Cyr A, Cyr LO, Cyr C. Acquired growth hormone deficiency and hypogonadotropic hypogonadism in a subject with repeated head trauma, or Tintin goes to the neurologist. CMAJ 2004;I7I(I2):I433-4.

8. Weir E, St. Lawrence R. Outbreak of neurologic syndrome and sequelae in 17 states and 2 provinces. $C M A J$ 2004;I7I(I2):I437-8.

9. Anonymous. Migraine treatments now and in the future. Headache 2004;44:846-50.

Io. Schackow TE, Chavez M, Loya L, et al. Audience response system: effect on learning in family medicine residents. Fam Med 2004;36:496-504.

II. Hoffman M, Mittelman M. Presentations at professional meetings: notes, suggestions and tips for speakers. Eur Intern Med 2004;15:358-63.

I2. Copeland HL, Longworth DL, Hewson MG, et al. Successful lecturing: a prospective study to validate attributes of the effective medical lecture. J Gen Intern Med 2000;15:366-7I. 